\title{
THE ELLIS PLATE OPERATION FOR SMITH'S FRACTURE
}

\author{
David J. Fuller, Bristol, England
}

Fracture of the lower end of the radius with anterior displacement of the distal fragment was described in 1847 by Robert William Smith and today this injury bears his name. The orthodox treatment of this fracture is reduction by manipulation followed by plaster fixation. Thomas (1957) showed that the fracture could be held in the reduced position with the wrist slightly flexed and the forearm fully supinated in a plaster including the elbow. Thomas also classified Smith's fracture into three different types (Fig. 1). Woodyard (1969) reviewed forty-one cases of Smith's fracture treated conservatively and he showed that, although the results were acceptable, it was difficult to produce a good result in the type of case referred to by Thomas as Type 2 .

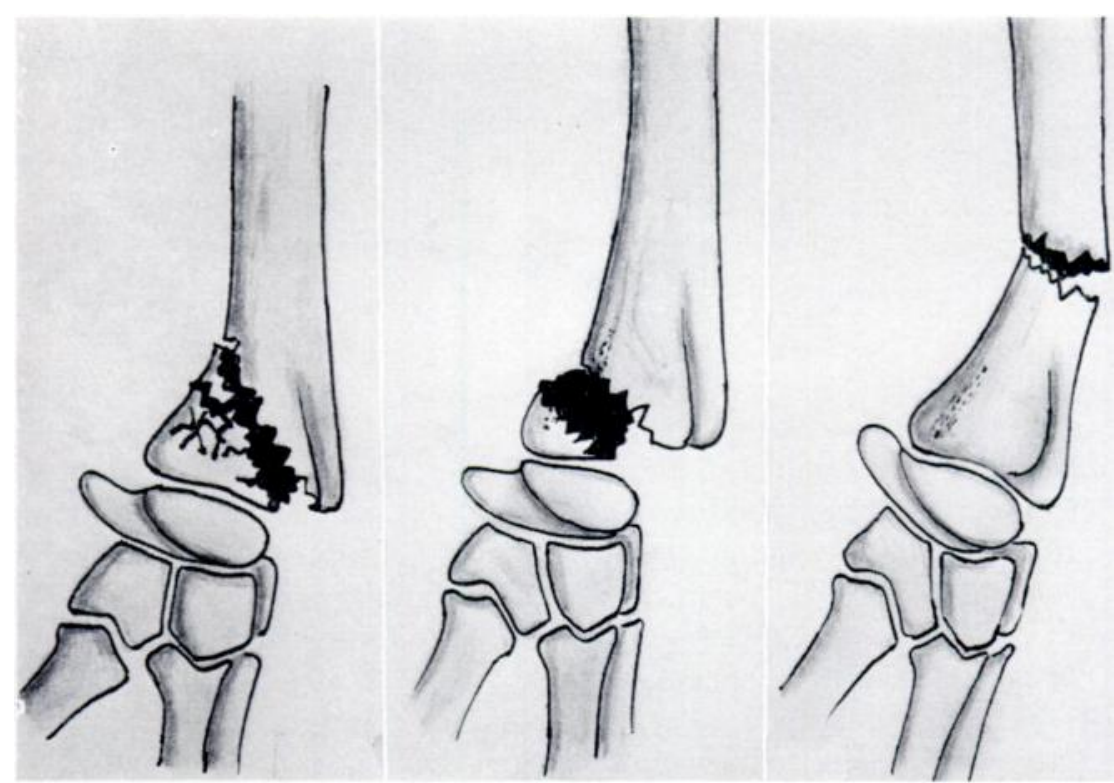

FIG. 1

The three types of Smith's fracture (Thomas 1957). Type 1 (left)-The line of the fracture is oblique and there is often comminution. The wrist joint is not subluxated. Type 2 (centre)-A small anterior marginal fracture. The carpus displaces with the distal fragment resulting in subluxation of the wrist joint. Type 3(right)-A transverse fracture not involving the wrist joint.

In 1965 Ellis described an operation for the internal fixation of the Smith's fracture with a small buttress plate screwed to the radial shaft. The purpose of the operation was to secure accurate reduction of the fracture, to ensure fixation, to prevent redisplacement, and to allow early mobilisation of the hand, wrist and forearm. The results of this operation are reviewed in this paper.

\section{MATERIAL}

Thirty-one patients who had been treated for Smith's fracture with the Ellis plate were personally examined. The operations had been carried out by consultant orthopaedic surgeons and the senior registrar in the Southampton area. The shortest period from operation to 
this review was one and a half years and the longest seven years. In all but two cases the operation had been performed within a week from the injury; the two exceptions were both in cases in which attempts to hold an unstable Smith's fracture with external splintage failed and operation was performed at two weeks and three weeks. The distribution of the cases and the sex incidence in relation to the classification described by Thomas are shown in Table I.

TABLE I

Fracture Types, Sex and Average Age

\begin{tabular}{|c|c|c|c|c|}
\hline \multicolumn{2}{|c|}{ Number of patients } & \multicolumn{3}{|c|}{ Type of fracture } \\
\hline \multirow{2}{*}{ Men } & & 1 & 2 & 3 \\
\hline & & 7 & 5 & 0 \\
\hline Women & . & 12 & 5 & 2 \\
\hline Total . & . & 19 & 10 & 2 \\
\hline Average & e (years) & 61 & 37 & 50 \\
\hline
\end{tabular}

\section{ASSESSMENT OF RESULTS}

Each patient gave his own account of the current function of the injured wrist and then an objective assessment was made on the basis of range of pronation and supination of the hand, range of flexion and extension of the wrist, persisting deformity, complications of the operation, and examination of radiographs, which were available in all cases to show the original injury, the position immediately after operation and the final position after union.

\section{RESULTS}

Twenty-eight of the thirty-one patients were very pleased with the result of the operation and did not admit to any residual disability. Range of rotation-Thirty patients had full rotation of the forearm. Range of wrist movement-Twelve patients had lost some wrist joint movement but in no case was the loss greater than 30 degrees of flexion or 30 degrees of extension. Deformity - The only persistent angular deformity seen was radial deviation at the fracture site. This was noted in eight patients, all of whom had suffered comminuted fractures of the type classed by Thomas as Type 1 .

Complications-The only important complication of the operation was delayed rupture of a deep flexor tendon at the level of the plate: the two cases in which this was recorded are described in more detail below. Seven of the plates in this series have so far been removed: in two cases the plate was removed at the time of tendon repair and in five others it was removed for minor symptoms.

Radiographic findings-Examination of the radiographs showed that in all thirty-one cases the fracture had united in the position obtained at operation. When the fracture had been plated in some degree of radial deviation the deformity did not increase after the operation.

\section{DISCUSSION}

Smith's fracture is an uncommon injury and this series is necessarily too small to allow of any statistically significant conclusions. Analysis of the results suggests certain features that may be of help in the management of any individual Smith's fracture.

Type 1 injury-Of the nineteen Type 1 fractures, eight united with some degree of radial deviation. As most of these fractures were comminuted and associated with instability of the ulnar side, as indicated by a fractured ulnar styloid process (Fig. 1), it is unlikely that plaster fixation would have been any more effective in preventing this particular deformity. It is 
interesting that, of these eight patients with radial displacement, all had full forearm rotation and only two had any significant loss of wrist movement. It may well be that radial deviation is an unavoidable result of the initial comminution and should be accepted without undue

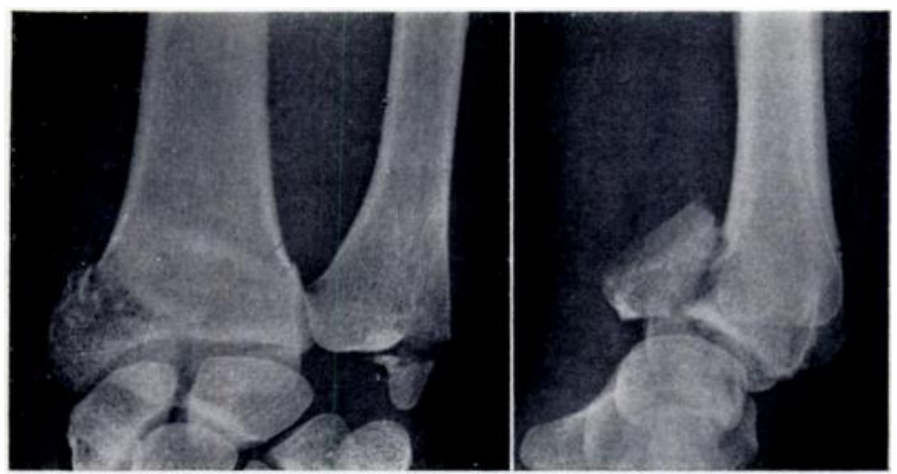

FIG. 2

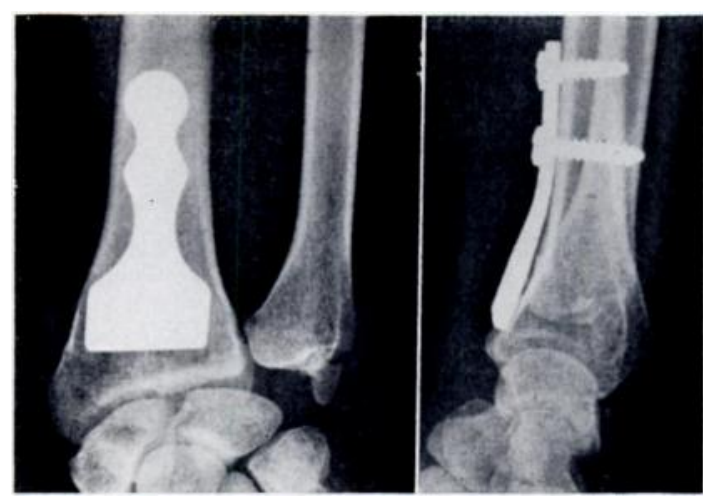

FIG. 3

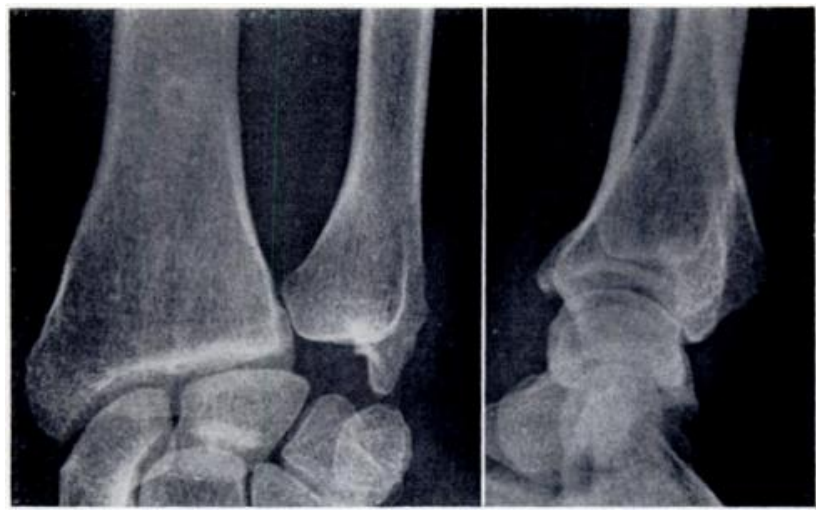

Fig. 4

Type 1 fracture. Figure 2-Before treatment. Figure 3-The position four months after plating. Figure $4-$ The appearance of the wrist four years later.

concern: provided the anterior shift of the distal fragment is reduced and held adequately, there should be no loss of rotation and the end-result will not be poor. A good result of primary plating of a Type 1 injury is shown in Figures 2 to 4 .

VOL. 55 B, NO. 1, FEBRUARY 1973 
Sometimes the Ellis plate was used when treatment by closed methods failed (Figs. 5 to 8). In the case illustrated, the patient had full function of the injured wrist when seen six years after operation.

Type 2 injury-Thomas stated that his Type 2 injury was the most unstable of the variants of the Smith's fracture. This is clearly a difficult injury to treat well with plaster alone: Woodyard found that all the poor results in his series of forty-one cases of Smith's fracture treated by manipulation and plaster fixation were in Type 2 injuries.

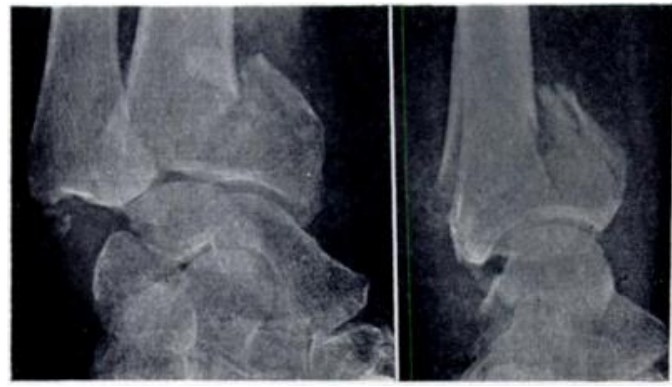

FiG. 5

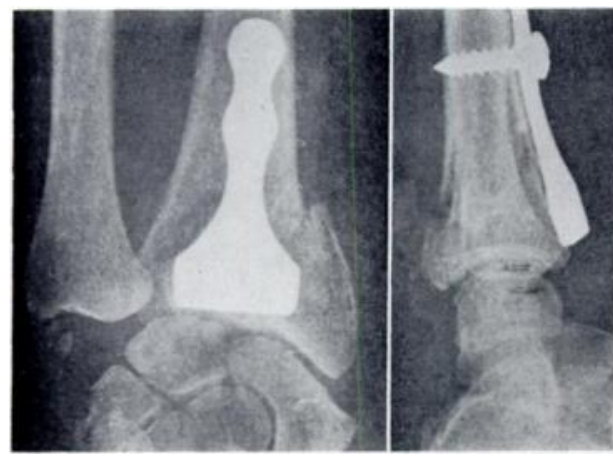

Fig. 7

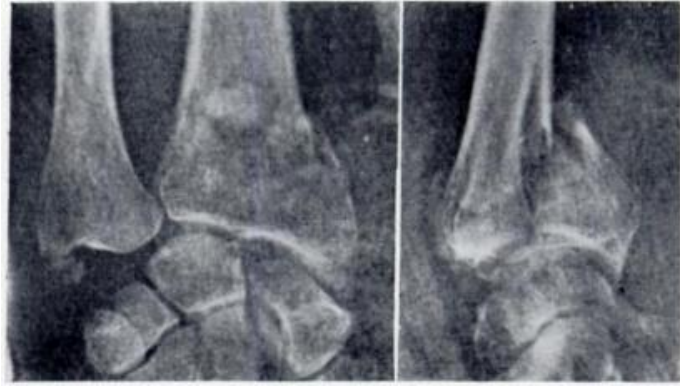

FIG. 6

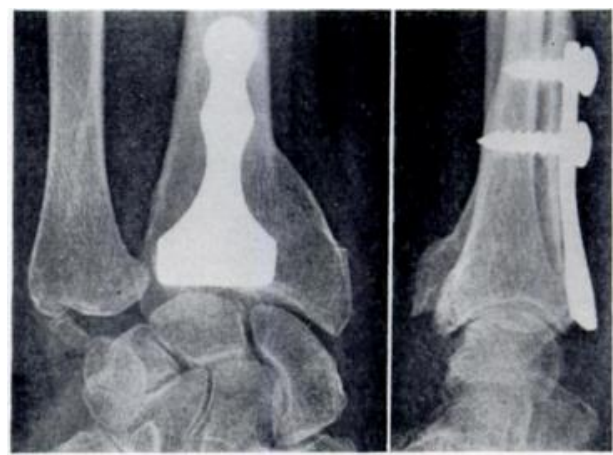

FIG. 8

Type 1 fracture. Figure 5-Before treatment. Figure 6-The unsatisfactory position in plaster. Figure 7 -The position after operation. Figure 8 - The appearance six years later.

There were ten fractures of this type in the present series. At review, seven of the patients were free from symptoms and were judged to have full function of the wrist and hand. Of the remaining three, two had restricted extension but were otherwise normal, and the third was the one patient in this series with some loss of forearm rotation. This man's fracture had been fixed in an unreduced position with the Ellis plate.

At operation for a Type 2 fracture, the small distal fragment, which is carrying the whole carpus anteriorly, is easily reduced and is held firmly by the Ellis plate because there is no comminution or lateral instability (Figs. 9 and 10). Mobilisation of the wrist and forearm is started immediately. Since failure to reduce this fracture means malunion with a subluxed carpus and, furthermore, since this particular type of injury is commonest in patients of twenty to forty years, it is imperative that perfect reduction is maintained until the fragments have united. Fixation with the Ellis plate seems to be the logical way to treat this type of injury and the results in this small series support this view.

Type 3 injury-There were only two patients with the Type 3 injury: both made a rapid and complete recovery. The three Type 3 fractures treated conservatively in Woodyard's series 
also did well. The Type 3 fracture differs basically from Types 1 and 2 in that it is a transverse fracture and is stable after reduction: it is adequately held in a forearm-wrist plaster in neutral rotation. Internal fixation with the Ellis plate is not indicated in the routine management of this injury.

Rupture of a deep flexor tendon-There were two instances of this complication. In the first, a woman aged forty-five sustained a Type 1 Smith's fracture of the right wrist. The fracture was fixed with an Ellis plate on the day of injury. The plate was placed too distally on the

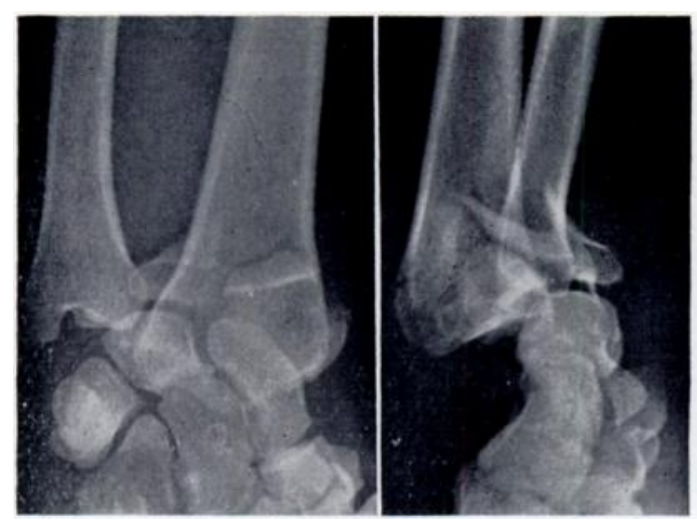

FiG. 9

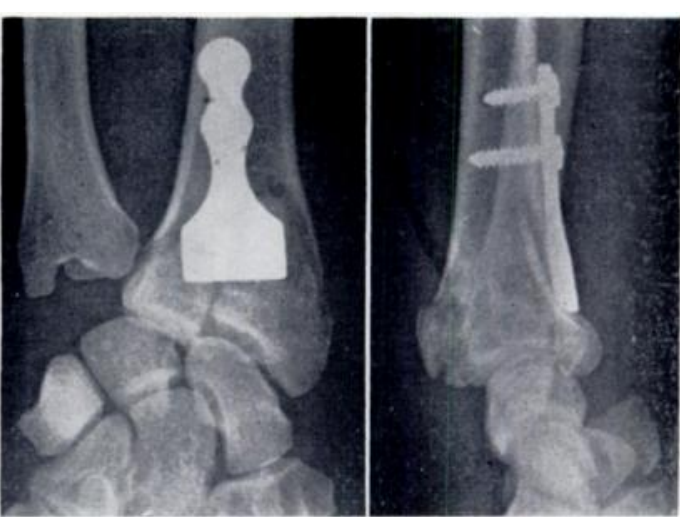

Fig. 10

Type 2 fracture with marked displacement. Figure 9-Before treatment. Figure 10-Restoration of the wrist joint after fixation.

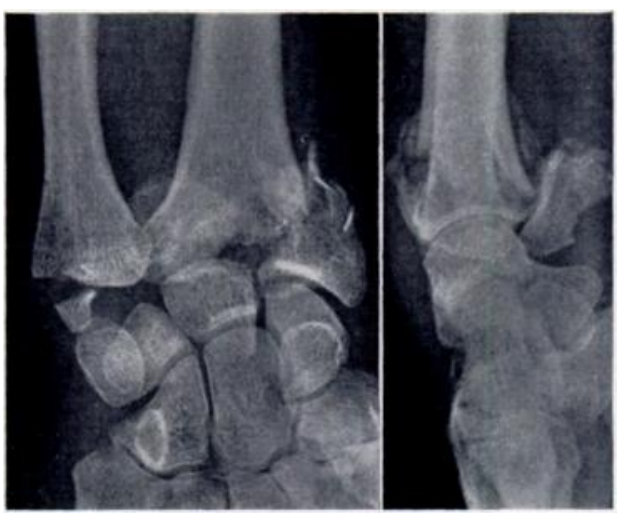

Fig. 11

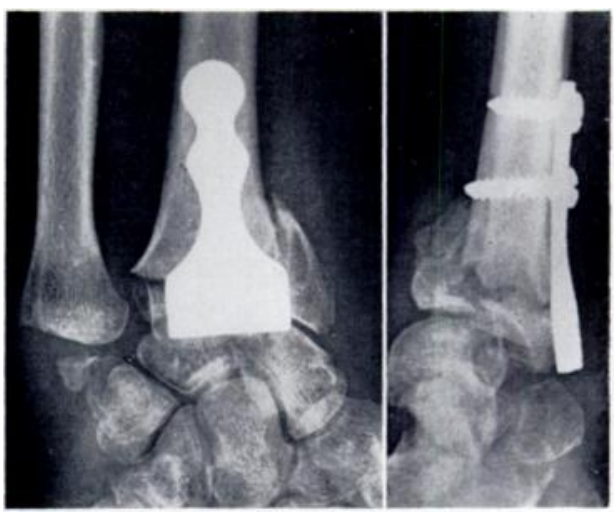

Fig. 12

Grossly comminuted Type 1 fracture. Figure 11-Before treatment. Figure 12-After open reduction and fixation with an Ellis plate. Note the prominent leading edge of the plate extending down beyond the level of the wrist joint.

radial shaft (Figs. 11 and 12). Six months after the injury there was spontaneous rupture of the flexor profundus tendon to the right index finger. At operation it was seen that the profundus tendon had worn against the leading edge of the plate. The plate was removed, and the tendon repaired.

The second case was that of a man of fifty with a Type 1 fracture that was fixed by an Ellis plate. The plate had to be placed obliquely in order to support a large separate fragment on the radial side (Fig. 13). The patient made a rapid recovery and returned to work. He came five years later with a sudden rupture of the right flexor pollicis longus tendon. At operation it was seen that the tendon had suffered attrition at the free edge of the plate. 
Clearly, particular care should be taken at operation to ensure that the leading edge of the plate lies in contact with the distal fragment. It is not necessary routinely to remove the plate after the fracture has united but it would be wise to advise removal of any plate that has been positioned too far down the radial shaft.

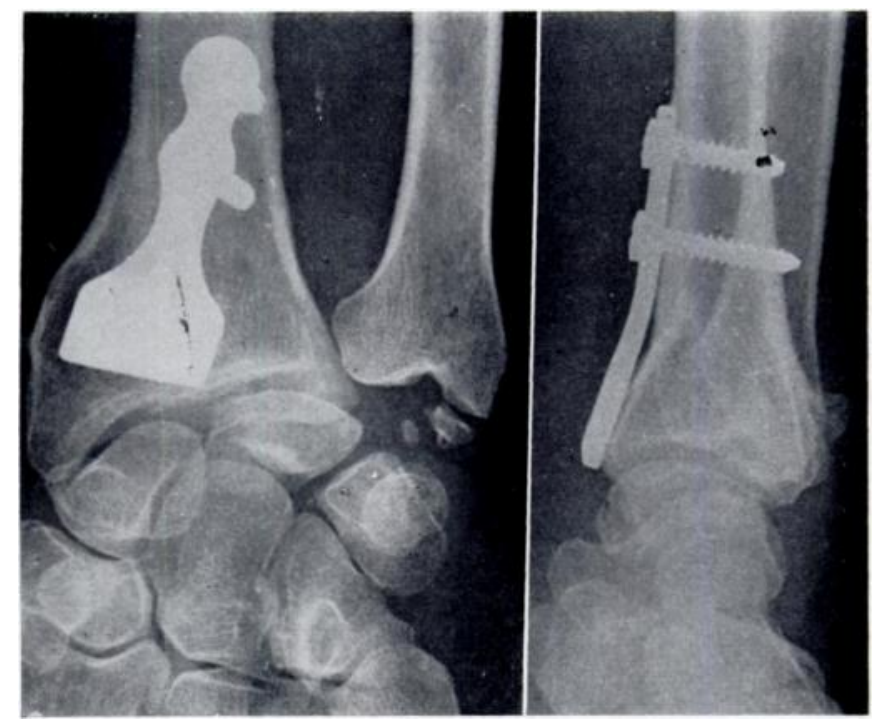

Fig. 13

Radiograph showing an obliquely positioned plate that was associated with late rupture of the tendon of flexor pollicis longus.

\section{SUMMARY}

1. Thirty-one patients treated with the Ellis plate for Smith's fracture have been examined and the results of the operation are presented.

2. The Type 1 fractures can usually be treated equally well by plaster or by internal fixation. The only compelling indication for open reduction and fixation with the Ellis plate is persistent anterior angulation at the fracture site despite the external splintage.

3. The Type 2 fracture should be treated by open reduction and fixation with the Ellis plate.

4. The Ellis plate is not indicated for the routine treatment of Type 3 fractures.

I wish to thank Professor J. S. Ellis and his colleagues at Southampton, Mr H. H. Langston, Mr D. C. Macrae and $\mathrm{Mr}$ J. Wilkinson, for permission to study their cases. I would also like to thank Mr G. Hampson for his drawings.

\section{REFERENCES}

Eluis, J. (1965): Smith's and Barton's Fractures. Journal of Bone and Joint Surgery, 47-B, 724.

SмIтH, R. W. (1847): Fractures of the Bones of the Fore-arm, in the Vicinity of the Wrist Joint. In $A$ Treatise on Fractures in the Vicinity of Joints, and on Certain Forms of Accidental and Congenital Dislocations, p. 129. Dublin: Hodges \& Smith.

Thomas, F. B. (1957): Reduction of Smith's Fracture. Journal of Bone and Joint Surgery, 39-B, 463.

WoOdyard, J. E. (1969): A Review of Smith's Fractures. Journal of Bone and Joint Surgery, 51-B, 324. 